\title{
Molecular Basis for the Heterogeneity of Human Tyrosinase
}

\author{
Shigeki Shibahara, ${ }^{*} †$ Yasushi Tomita, $\neq$ Hachiro \\ Tagami, $\ddagger$ Rita M. Müller* and Tirza Cohen*§ \\ ${ }^{*}$ Friedrich Miescher-Institut, PO Box 2543, CH-4002 \\ Basel, Switzerland, †Department of Applied Physiology \\ and $\ddagger$ Department of Dermatology, Tohoku University \\ School of Medicine, Sendai 980
}

\begin{abstract}
Shibahara, S., Tomita, Y., Tagami, H., Müller, R.M. and Cohen, T. Molecular Basis for the Heterogeneity of Human Tyrosinase. Tohoku J. exp. Med., 1988, 156 (4), 403-414 - A cDNA clone, pHT $\gamma 1$, representing human tyrosinase mRNA was isolated by screening a melanoma cDNA library with a synthetic oligonucleotide complementary to a segment of the human tyrosinase cDNA, Pmel 34 [Kwon et al. (1987) Proc. nat. Acad. Sci. USA 84, 7473-7477]. However, there are a number of differences in the nucleotide sequence between two cDNAs, $\mathrm{pHT} \gamma \mathrm{l}$ and Pmel 34, particularly in the region coding for the carboxyl terminus of the enzyme (putative exon 5). We therefore cloned the genomic DNA segment carrying the exon 5 of the human tyrosinase gene by screening a human placental genoruic DNA library with a cloned cDNA probe. The nucleotide sequences of human tyrosinase cDNA as well as a part of its gene were determined. Mature human tyrosinase is composed of 511 amino acids with a molecular weight of 58,000 . We provide evidence for the presence of at least two species of human tyrosinase mRNA generated by alternative splicing in human pigmented melanoma cells. ——_ tyrosinase; melanin pigment; cDNA; gene; alternative splicing
\end{abstract}

Tyrosinase (EC 1.14.18.1) is a multi-functional copper-containing enzyme that is essential for melanin biosynthesis in pigment cells (Lerner et al. 1950). It catalyzes the conversion of tyrosine to dihydroxyphenylalanine (dopa), and dopa to dopaquinone, which are referred to as tyrosine hydroxylase activity and dopa oxidase activity, respectively (Pomerantz 1966). Previous studies showed by polyacrylamide gel electrophoresis the presence of three or four different forms of tyrosinase (Shimao 1962; Burnet et al. 1967; Pomerantz and Li 1973; Hearing et al. 1981). However, no information is available whether such a heterogeneity of tyrosinase resides in the gene level.

Received November 10, 1988; revision accepted for publication November 21, 1988. §Present address: Department of Human Genetics, Hadassah University Hospital, PO Box 12000, Jerusalem 91120, Israel.

Correspondence to S. Shibahara, M.D., Ph.D., Department of Applied Physiology, Tohoku University School of Medicine, Sendai 980, Japan. 
We have isolated a pigment cell-specific mouse cDNA, pMT4, and provided evidence that it encodes tyrosinase (Shibahara et al. 1986). Recently, other groups have isolated and sequenced another $c D N A$ s encoding mouse tyrosinase (Yamamoto et al. 1987; Kwon et al. 1988; Müller et al. 1988) and a cDNA for human tyrosinase, Pmel 34 (Kwon et al. 1987). Furthermore, it was shown that the mouse tyrosinase cDNA, pmcTyrl (Müller et al. 1988), encodes a protein possessing tyrosine hydroxylase activity, namely functional tyrosinase. The amino acid sequence deduced from the nucleotide sequence of pmcTyrl shows about $40 \%$ homology with the entire region of mouse tyrosinase deduced from pMT4 (Shibahara et al. 1986). It is therefore conceivable that there may be at least two tyrosinase isozymes encoded by two distinct genes, and that the enzyme protein encoded by pMT4 may possess dopa oxidase activity instead of tyrosine hydroxylase activity. In this report, however, we have termed the protein encoded by Pmel 34 (Kwon et al. 1987) or pmcTyrl (Müller et al. 1988) as tyrosinase.

Comparison of mouse and human tyrosinase reveals that the two enzymes are about $80 \%$ identical except for the carboxyl termini (Kwon et al. 1987; Müller et al. 1988). In spite of the differences in the deduced amino acid sequences of carboxyl termini between human and mouse tyrosinase, the nucleotide sequences encoding the carboxyl termini have about $75 \%$ homology. Furthermore, the molecular weight (Mr) of mature human tyrosinase deduced from Pmel 34 is about 63,000 (Kwon et al. 1987), which appears too big for human tyrosinase of $\mathrm{Mr}$ 58,000 (Nishioka 1978). We therefore wanted to reexamine the nucleotide sequence of human tyrosinase cDNA. Since our aim is to clarify the molecular basis of human albinism, it is of vital significance to know the correct amino acid sequence of tyrosinase. Consequently, we cloned and sequenced the cDNA encoding human tyrosinase, and deduced its amino acid sequence. Furthermore, we present evidence that there are at least two mRNA species for human tyrosinase, which may be generated by alternative splicing. Our observations could provide the molecular basis for the heterogeneity of tyrosinase.

\section{Materials and Methods}

Preparation of $R N A$

Total RNA was prepared from MeWo human melanoma cells (Brüggen et al. 1981). Poly (A) ${ }^{+}$RNA was isolated by oligo(dT)-cellulose chromatography (Aviv and Leder 1972).

Isolation of human tyrosinase cDNA clone and genomic clone

A cDNA library was constructed by the method of Okayama and Berg (1982) using 2 $\mu \mathrm{g}$ of MeWo melanoma poly $(\mathrm{A})^{+} \mathrm{RNA}$, and screened with the ${ }^{32} \mathrm{P}$-end-labeled synthetic oligonucleotide that is complementary to the nucleotide residues $244 / 276$ of Pmel 34 (Kwon et al. 1987). This region was chosen because of a good similarity between the human and mouse cDNA sequences (Kwon et al. 1987; Yamamoto et al. 1987). The human genomic DNA library used was a collection of recombinant phage that contain human placental DNA fragments generated by partial digestion with Sau3AI and joined to EMBL3 arms. The 
hybridization probe was the ${ }^{32} \mathrm{P}-$ labeled PvuII/NdeI fragment (931/1794) derived from pHT $\gamma 1$ (see Fig. 1). Nucleotide sequences were determined by the method of Maxam and Gilbert (1980).

\section{RNA blot hybridization}

MeWo RNA and HeLa cell RNA were subjected to electrophoresis as described previously (Shibahara et al. 1986), transferred to a nitrocellulose filter, and hybridized with ${ }^{32} \mathrm{P}$-labeled fragment of human tyrosinase cDNA. The DNA probe used in this study was labeled with $\left[\alpha^{-{ }^{32}} \mathrm{P}\right] \mathrm{dCTP}$ by the method of Feinberg and Vogelstein (1983), and is indicated in the figure legend. The markers were human rRNA.

\section{S1 nuclease-mapping analysis}

The S1 probe was the PstI/BgIII fragment (vector/1314) derived from the $\mathrm{pHT} \gamma 1$ (see Fig. 1). The PstI site is located in the Okayama-Berg vector (1982). The probe was hybridized to total RNA $(20 \mu \mathrm{g})$ prepared from MeWo melanoma cells or HeLa cells, and digested with Sl nuclease as described (Müller et al. 1987).

\section{Reagents}

Restriction endodeoxyribonucleases were obtained from Bethesda Research Laboratories (Rockvilole, MD, USA), Pharmacia (Uppsala, Sweden) and Boehringer (Mannheim, FRG), oligo (dT)-cellulose type 7 and Okayama-Berg vector from Pharmacia. EMBL3 arms, $\left[\alpha^{-32} \mathrm{P}\right] \mathrm{dCTP}$ (specific activity, 3,000 Ci/mmole) and $\left[\gamma^{-{ }^{2}} \mathrm{P}\right] \mathrm{ATP}$ (specific aetivity, $5,000 \mathrm{Ci} /$ mmole) were purchased from Amersham International (Buckinghamshire, UK).

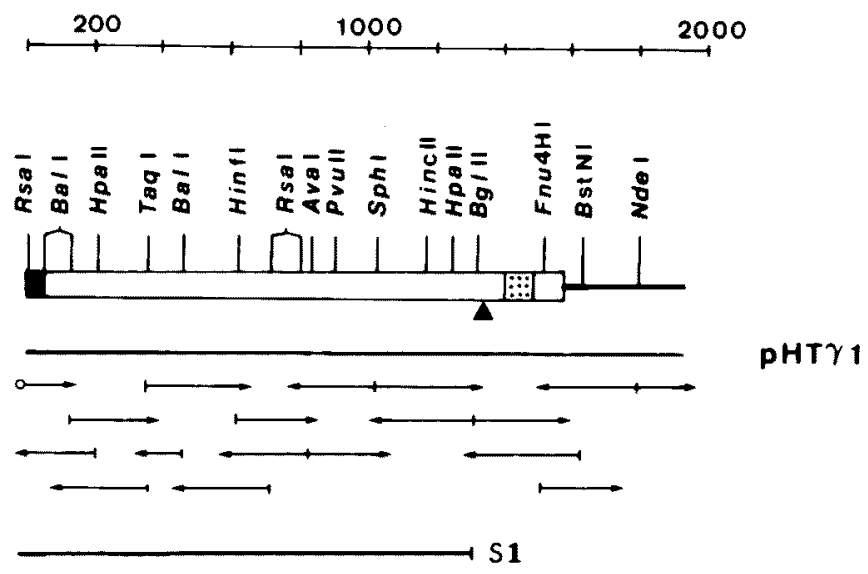

Fig. 1. Restriction map and sequencing strategy of cloned cDNA, $\mathrm{pHT} \gamma \mathrm{l}$, encoding human tyrosinase. The restriction map shows only relevant sites. The protein-coding region is indicated by an open box, in which the putative transmembrane segment is stippled. The closed box indicates the putative signal peptide. The arrows indicate the direction and extent of sequence determinations. The short vertical lines and the open circle at the end of arrows indicate the sites of 5 -end labeling located in the cDNA and the vector DNA, respectively. The location of an intron (putative intron 4) is indicated by a triangle. The $\mathrm{Sl}$ probe used in Fig. 5 is also shown. 


\section{Results and Discussion}

cDNA cloning of human tyrosinase

From $2 \times 10^{4}$ transformants of MeWo human melanoma cDNA library, we have isolated three hybridization-positive clones and characterized the longest cDNA clone, $\mathrm{pHT}_{\gamma \mathrm{l}}$ (Fig. 1). The $\mathrm{pHT} \gamma \mathrm{l}$ is not a full-length cDNA, but contains the entire protein-coding region for mature tyrosinase. The size of human tyrosinase mRNA was estimated by blot hybridization analysis of total RNA prepared from MeWo human melanoma cells (Fig.2, lane 1). The tyrosinase $\mathrm{mRNA}$ is about 2,000 nucleotides long, and is not detectable in HeLa cells (lane 2), suggesting that this mRNA is pigment cell-specific.

Nucleotide sequence of human tyrosinase cDNA

The nucleotide sequence of the message strand of the human tyrosinase cDNA, $\mathrm{pHT}_{\gamma} 1$ is shown in Fig. 3 . The $\mathrm{pHT} \gamma 1$ lacks the region near $5^{\prime}$-terminus of its mRNA including the initiating methionine. However, based on the nu-

\section{2}

\section{$28 \mathrm{~S}-$}

\section{$18 \mathrm{~S}-$}

Fig. 2. Autoradiogram of blot hybridization analysis of human tyrosinase mRNA. Each lane contained $8 \mu \mathrm{g}$ total RNA prepared from MeWo melanoma cells (lane 1) and HeLa cells (lane 2). The hybridization probe was the ${ }^{32} \mathrm{P}$-labeled HpaII/HpaII fragment (213/1248) derived from $\mathrm{pHT} \gamma 1$. The size markers were human rRNA. 
cleotide sequences of human (Kwon et al. 1987) and mouse (Yamamoto et al. 1987 ; Müller et al . 1988) tyrosinase cDNAs as well as of mouse tyrosinase gene (Ruppert et al. 1988), we tentatively assign the CAT codon (nucleotide residues $39 / 41$ ) as the first amino acid residue of the mature human tyrosinase. The synthetic oligonucleotide used as a hybridization probe is complementary to the nucleotide residues $269 / 299$ of the $\mathrm{pHT} \gamma 1$, Fig. 3 ). The translation termination codon TAA is present in the assigned reading frame at position (1572/1574) and is followed by about 300 nucleotides of the $3^{\prime}$-untranslated region.

There are a number of differences in the nucleotide sequences of the cDNAs encoding human tyrosinase, $\mathrm{pHT}_{\gamma} 1$ and Pmel 34 (Kwon et al. 1987) (marked in Fig. 3). For example, two deletions are present in the protein-coding region near amino-terminus of Pmel 34. The $\mathrm{G}$ residue at the position 108 and the $\mathrm{CC}$ dinucleotide at the positions 118/119 of pHT $y 1$ are deleted in Pmel 34. These deletions present in Pmel 34 resulted in frame shifts but only in small regions. The sequence of mouse tyrosinase cDNA pmcTyrl (Müller et al. 1988) favors the sequence of $\mathrm{pHT} \gamma 1$. Furthermore, there are two base changes (C residue at 559 and $\mathrm{G}$ residue at 907 of $\mathrm{pHT} \gamma \mathrm{l}$ ), which also result in amino acid substitutions.

In the putative exon 3 region indicated by a dotted underline in Fig. 3 , the Pmel 34 contains four deletions of single nucleotide (nucleotide residues 1101, 1104,1120 and 1148 of $\mathrm{pHT}_{\gamma} 1$ ) and one insertion of the G residue (1152 of Pmel 34 ), which therefore caused frame shifts only in short regions. Furthermore, there are two base changes (1135 and 1189 of $\mathrm{pHT}_{\gamma} \mathrm{l}$ ), which also resulted in amino acid substitutions. These nucleotide differences are of particular significance, because these regions code for the putative copper-binding site (see Fig. 4). The nucleotide sequence of mouse tyrosinase cDNA, pmcTyrl (Müller et al. 1988) reveals the deletion of 148 nucleotides in the aberrant mouse tyrosinase cDNA, Tyrs-33 (Yamamoto et al. 1987) (Fig. 3), and always favors the sequence of pHT $\gamma 1$. Recently, Kwon et al. (1988) corrected a part of the sequence errors in human tyrosinase cDNA, Pmel 34 (Kwon et al. 1987) and their corrected sequence is identical to the sequence of $\mathrm{pHT}_{\gamma 1}$ (nucleotide residue 1135/1180).

In the 3 -region, there are two deletions of single nucleotide (1644 and 1667

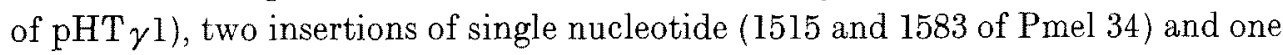
base change (1468 of $\left.\mathrm{pHT}_{\gamma} 1\right)$. The most critical difference is the insertion of $\mathrm{A}$ residue (nucleotide residue 1515 of Pmel 34,), which caused a frame shift and changed the deduced amino acid sequence of the entire carboxyl terminus. This frame of Pmel 34 thus codes for a longer peptide. In order to confirm the nucleotide sequence of the $\mathrm{pHT}_{\gamma}$, we have isolated a genomic clone harboring the 3 -end of the pHT $\gamma 1$ (nucleotide residues 1351/1866, putative exon 5) and determined its nucleotide sequence. Sequence analysis of the cloned gene reveals that the location of the intron (putative intron 4 ) is between the nucleotide residues 1350 and 1351 of the $\mathrm{pHT} \gamma \mathrm{l}$ (indicated by a vertical line in Fig. 3). The nucleotide sequence of the putative exon 5 is same as that of $\mathrm{pHT}_{\gamma} 1$. Moreover, 
3 TACTGCCTGCTGTGGAGTTCCAGACCTCCGCTGGCCATTTCCCTAGAGCCTGTGTCTCC TyrCysLeuLeuTrpSerPheGInThrSerAlaGlyHisPheProArgAlaCysvalser $-10$ $-1 \quad 1$

63 TCTAAGAACCTGATGGAGAAGGAATGCTGTCCACCGTGGAGCGGGḠACAGGAGTCC̄C̄TGT SerLysAsnLeuMetGluLysGluCysCysProProTrpSerGlyAspArgSerProCys 10 20

123 GGCCAGCTTTCAGGCAGAGGTTCCTGTCAGAATATCCTTCTGTCCAATGCACCACTTGGG GIYGInLeuSerGIYArgGlySerCysGInAsn I leLeuLeuSerAsnAlaP roLeuGly 30 40

183 CCTCAATTTCCCTTCACAGGGGTGGATGACCGGGAGTCGTGGCCTTCCGTCTTTTATAAT ProGlnPheProPheThrGlyValAspAspArgGluSerTrpProSerValPheTyrAsn 50 60

243 AGGACCTGCCAGTGCTCTGGCAACTTCATGGGATTCAACTGTGGAAACTGCAAGTTTGGC ArgThrCysGlnCysSerGlyAsnPheMetGlyPheAsnCysGlyAsnCysLysPheGly 70 80

303 TTTTGGGGACCAAACTGCACAGAGAGACGACTCTTGGTGAGAAGAAACATCTTCGATTTG PheTrpGlyProAsnCY STrGluArgArgLeuLeuValArgArgAsnIlePheAspLeu 90 100

363 AGTGCCCCAGAGAAGGACAAATTTTTTGCCTACCTCACTTTAGCAAAGCATACCATCAGC SerAlaProGluLysAspLysPhePheAlaTyrLeuThrLeuAlaLysHisThrIleSer 110

423 TCAGACTATGTCATCCCCATAGGGACCTATGGCCAAATGAAAAATGGATCAACACCCATG SerAspTyrValI leP roI leGlyThrTyrGlyGlnMetLysAsnGlySerThrProMet 130 140

483 TTTAACGACATCAATATTTATGACCTCTTTGTCTGGATGCATTATTATGTGTCAATGGAT PheAsnAspI leAsnIleTyrAspLeuPheValTrpMetHisTyrTyrVal SerMetAsp 150 160

543 GCACTGCTTGGGGGATCTGAAATCTGGAGAGACATTGATTTTGCCCATGAAGCACCAGCT Al aLeuLeuGlyGly SérGluI le TrpArgAsp I leAspPheAl aH isGluAl aProAla 170 180

603 TTTCTGCCTTGGCATAGACTCTTCTTGTTGCGGTGGGAACAAGAAATCCAGAAGCTGACA PheLeuP roTrpHisArgLeuPheLeuLeuArgTrpGluGlngluIleGlnLysLeuThr 190 200

663 GGAGATGAAAACTTCACTATTCCATATTGGGACTGGCGGGATGCAGAAAAGTGTGACATT GlyAspGluAsnPheThrI leProTyrTrpAspTrpArgAspAlaGluLysCysAspIle 210 220

723 TGCACAGATGAGTACATGGGAGGTCAGCACCCCACAAATCCTAACTTACTCAGCCCAGCA CysThrAspGluTyrMetGlyGlyGlnHisProThrAsnProAsnLeuLeuSerProAla 230 240

783 TCATTCTTCTCCTCTTGGCAGATTGTCTGTAGCCGATTGGAGGAGTACAACAGCCATCAG SerPhePheSerSerTrpGlnI levalCysSerArgLeuGluGluTyrAsnSerHisGln 250 260

843 TCTTTATGCAATGGAACGCCCGAGGGACCTTTACGGCGTAATCCTGGAAACCATGACAAA

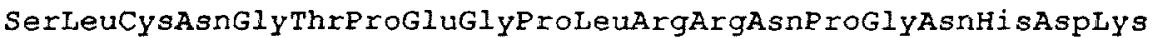
270 280

903 TCCAGAACCCCAAGGCTCCCCTCTTCAGCTGATGTAGAATTTTGCCTGAGTTTGACCCAA SerArgThrProArgLeuProSerSerAlaAspValGluPheCysLeuSerLeuThrGin 290 300

963 TATGAATCTGGTTCCATGGATAAAGCTGCCAATTTCAGCTTTAGAAATACACTGGAAGGA TyrGluSerGlySerMetAsplysAlaAlaAsnPheSerPheArgAsnThrLeuGluGl y 310 320

1023 TTTGCTAGTCCACTTACTGGGATAGCGGATGCCTCTCAAAGCAGCATGCACAATGCCTTG

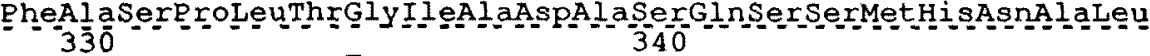

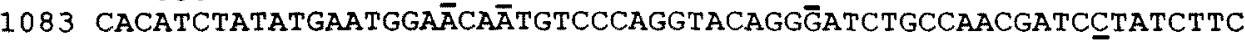
His I IeTyrMetAsnglyThrMetSerGinValGlngly SerAlaAsnAspProIlephe $350^{-}$

1143 CTTCTTCACCATGCATTTGTTGACAGTATTTTTGAGCAGTGGCTCCGAAGGCACCGTCCT LeuLeuHisHisAlaPheValAspSerI lePheGluGln r r LeuÁrgArgHi sArgPro $370^{\circ}$ 380 
1203 CTTCAAGAAGTTATCCAGAAGCCAATGCACCCATTGGACATAACCGGGAATCCTACATG LeuGlnGluVal TyrP rOGluAlaAsnAlaProI leGlyH isAsnArgGl userTyrMet 390

1263 GTTCCTTTTATACCACTGTACAGAAATGGTGATTTCTTTATTTCATCCAAAGATCTGGGC ValProPheI leProLeuTyrArgAsnGlyAspPhePheI leSerSerLysAspLeuGly 410

1323 TATGACTATAGCTATCTACAAGATTCAGACCCAGACTCTTTTCAAGACTACATTAAGTCC TyrAspTyrSerTyrLeuGlnAspSerAspProAspSerPheGlnAspTyrIleLysSer 430 440

1383 TATTTGGAACAAGCGAGTCGGATCTGGTCATGGCTCCTTGGGGCGGCGATGGTAGGGGCC TyrLeuGluGlnAlaSerArg I leTrpSerTrpLeuLeuGlyAlaAlaMetValGlyAla 450

1443 GTCCTCACTGCCCTGCTGGCAGGGCTTGTGAGCTTGCTGTGTCGTCACAAGAGAAAGCAG ValLeuThrAlaLeuLeuAlaGlyLeuValserLeuLeuCysArgHisLysArgLysGin 470 480

1503 CTTCCTGAAGAAAAGCAGCCACTCCTCATGGAGAAAGAGGATTACCACAGCTTGTATCAG LeuP roGluGluLY SGInP roLeuLeuMetGluLy SGluAspTyrHisserLeuTyrGin

490
1563 AGCCATTTATAAAAGGCTTAGGCAATAGAGTAGGGCCAAAAAGCCTGACCTCACTCTAAC

490
1563 AGCCATTTATAAAAGGCTTAGGCAATAGAGTAGGGCCAAAAAGCCTGACCTCACTCTAAC SerHisLeuEnd 510

1623 TCAAAGTAATGTCCAGGTTCCD̄AGAGAATATCTGCTGGTATTTTT̄CTGTAAAGACCATTT

1683 GCAAAATTGTAACCTAATACAAAGTGTAGCCTTCTTCCAACTCAGGTAGAACACACCTGT

1743 CTTTGTCTTGCTGTTTTCACTCAGCCCTTTTAACATTTTCCCCTAAGCCCATATGTCTAA

1803 GGAAAGGATGCTATTTGGTAATGAGGAACTGTTATTTGTATGTGAATTAAAGTGCTCTTA

1863 TTTT

Fig. 3. Nucleotide sequence of cDNA encoding human tyrosinase and its deduced amino acid sequence. The nucleotide sequence of the message strand is shown. Nucleotides are numbered in the $5^{\prime}$ to $3^{\prime}$ direction and nucleotide residue 1 is the $5^{\prime}$-end of eDNA. The deduced amino acids are shown below the nucleotide sequences and are numbered beginning with the amino-terminal residue of the mature tyrosinase. The preceding residues of a putative signal peptide are indicated by negative numbers. The TG dinucleotide at the $5^{\prime}$-end of the $\mathrm{pHT} \gamma 1$ is not shown (nucleotide residues 1-2). The overlines indicate the nucleotides present in $\mathrm{pHT} \gamma 1$, but deleted in Pmel 34 (Kwon et al. 1987); short underlines, nucleotide differences; and arrow heads, locations of nucleotides absent in $\mathrm{pHT}_{\gamma} 1$, but present in Pmel 34. The location of an intron is indicated by a solid vertical line. The dotted vertical lines indicate the possible locations of introns. The dotted underline indicates the region that is deleted in the mouse tyrosinase cDNA, Tyrs-33 (Yamamoto et al. 1987). The transmembrane segments are indicated by long underlines.

the nucleotide sequences of mouse tyrosinase CDNAs, MTY811 and pmeTyrl favor the sequene of $\mathrm{pHT} \gamma \mathrm{l}$. Blot hybridization analysis of human placental DNA suggested that there is a single gene for human tyrosinase (data not shown). It is therefore unlikely that the differences in the sequence of $\mathrm{pHT} \gamma \mathrm{l}$ are caused by cloning artifacts, such as errors of reverse transcription.

Amino acid sequence of human tyrosinase

The deduced sequence of the first 18 amino acid residues of the mouse tyrosinase (Müller et al. 1988) has a feature characteristic of the signal peptide of 
secretory and membrane-associated protein. Although both human tyrosinase cDNAs, Pmel 34 (Kwon et al. 1987) and pHT $\gamma 1$, lack the $5^{\prime}$-end of mRNA, comparison of the nucleotide sequence of Pmel 34 with mouse tyrosinase cDNAs (Müller et al. 1988) suggests that Pmel 34 may lack only one amino acid residue, namely initiating methionine. We therefore assume that a possible cleavage site for a signal peptide is after the glycine residue at position -1 (Fig. 3). Mature

1 HFPRACVSSKNLMEKECCPPWSGDRSPCGQLSGRGSCQNILLSNAPLGPQFPFT GVDDRE

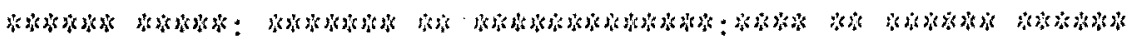

1 HFPRACASSKNLLAKECCPPWMGDGSPCGQLSGRGSCQDILLSSAPSGPQFPFKGVDDRE

61 SWPSVFYNRTCQCSGNFMGFNCGNCKFGFWGPNCT ERRLLURRNIFDL SAPEKDKFFAYL

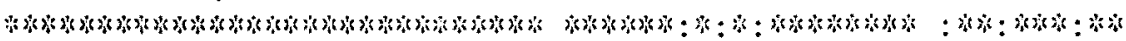

61 SWPSVFYNRTCQCSGNFMGFNCGNCKFGFGGPNCT EKRVL IRRN I FDLSUSEKNKFFSYL

121 TLAKHT ISSDYVIPIGTYGQMKNGSTPM FNDINIY DLFVWMHYYVSMDALLGGSEIWRDI (2)

121 TLAKHT ISSUYVIPTGT YGQMNNGSTPMFNDINIYDLFVGMHYYUSRDTLLGGSEIWRDI

181 DFAHEAPAFLPHHRLFLLRWEQEIQKLTGDENFTIPYWDWRDAEKCDICTDEYMGGQHPT

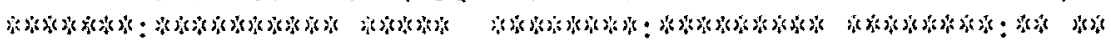

181 DFAHEAPGFLPWHRLFLLLWEGEIRELT GDENFTVPYWDHRDAENCDI CTDEYLGGRHPE

241 NPNLLSPASFFSSHQI VCSRLEEYNSHQSL CNGTPEGPLRRNPGNHDKSRTPRLPSSADV

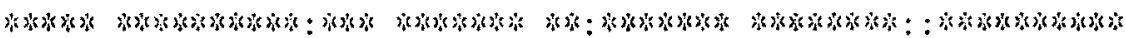

241 NPNLLIPASFFSSWQI I CSRSEEYNSHQVLCDGTPEGPLLRNPGNHDKAKTPRLPSSADV

301 EFCLSLTQYESGSMDKAANFSFRNTLEGFASPLTGIADASQSSMHNAL HIYMNGTNSQVQ

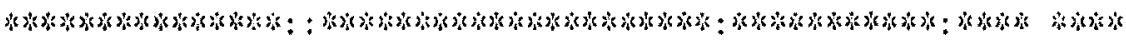

301 EFCLSLTQYESGSMDRT AN FSFRNTLEGFASP LTGI ADPSQSSMHNALHIFMNGTMSQVQ

361 GSANOPIFLLHHAFVDSIFEQWLRRHRPLQEVYPEANAFI GHNRESYMUPF IPLYRNGDF

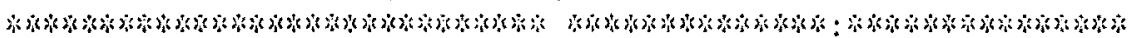

361 GSANDPIFLLHHAFVDSIFEQWLRRHRPLLEVYPEANAFI GHNRDS YMVPFIPL YRNGDF

421 FISSKDLGYDYSYLQDSDPDSFQDYIKSYLEQASRIWSWLLGAAMVGAVLTALLAGLVSL

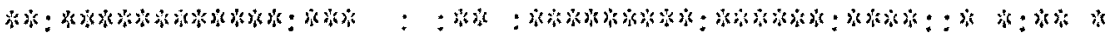

421 FITSKDLGYDYSYLGESDPGFYRNYIEPYLEQASRIWPWLLGAALVGAVIAAALSGLSSR

481 LCRHKRK ...QLPEEKQPLLMEKEDYHSL. YQSHL

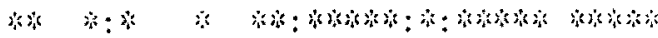

481 LCLQRKKKKKQPQEERQPLLMDKDDYHSLLYQSHL

Fig. 4. Homology in the amino acid sequences of human and mouse tyrosinase. The sequences are shown by the single-letter code. The top line indicates the mature human tyrosinase deduced from the nucleotide sequence of $\mathrm{pHT}_{\gamma 1}$, and the bottom line indicates the mouse tyrosiase deduced from pmcTyr1 (Müller et al. 1988). The asterisk indicates the identical amino acids found in both sequences; (:) the chemically similar amino acids. Putative copperbinding regions are indicated by underlines. 
human tyrosinase is thus composed of 511 amino acids of $\mathrm{Mr} 58,000$; this value is similar to that reported for the purified human tyrosinase (Nishioka 1978) as well as those for mature mouse tyrosinase deduced from MTY 881 (Kwon et al. 1988) and pmcTyrl (Müller et al. 1988). Human tyrosinase also contains a putative transmembrane segment near the carboxyl terminus (residues $456-481$ ) as indicated by an underline in Fig. 3.

The alignment of the amino acid sequences of human and mouse tyrosinase is shown in Fig. 4. Human tyrosinase is shorter than mouse enzyme by four amino acids at the carboxyl terminus. The degree of sequence homology is about $86 \%$. Human tyrosinase contains 17 histidine residues, and all of them are also conserved in mouse enzyme (Müller et al. 1988). Recently, Lerch (1988) compared the amino acid sequences of bacterial, fungal and mouse tyrosinase and indicated two regions as potential copper-binding sites, which is also supported by a structural similarity between tyrosinase and hemocyanins, the copper-containing dioxygen carriers (R. Lontie, personal communication). Based on their comparisons, we tentatively assign two regions, amino acid residues $154-220$ and 343-385, as the copper-binding sites of human tyrosinase (Fig. 4), which could provide the ligands of the first copper atom, designated as $\mathrm{Cu}(\mathrm{A})$, and the second copper atom, $\mathrm{Cu}(\mathrm{B})$, respectively (Lerch 1988). In each copper-binding site, three or four histidine residues are present in both human and mouse tyrosinase. It is therefore conceivable that some of these histidine residues may serve as the ligands of two coppers of tyrosinase (Nishioka 1978).

Mature human and mouse tyrosinase contain 16 cysteine residues at equivalent positions (Fig. 4). Ten cysteine residues are present within the 100 residues at the amino-terminus. Five cysteine residues are clustered between two copperbinding regions. There are six potential N-glycosylation sites (Marshall 1974; Bause 1983) conserved in both human and mouse tyrosinase (asparagine residues $68,93,143,212,319$ and 353 ). Since human tyrosinase contains four asparaginelinked sugar chains per molecule (Ohkura et al. 1984), some of these residues are the functional $\mathrm{N}$-glycosylation sites.

\section{Presence of aberrant species of human tyrosinase $m R N A$}

The aberrant mouse tyrosinase cDNA, Tyrs-33 (Yamamoto et al. 1987) lacks 148 nucleotides, which are the entire sequence of the exon 3 of the mouse tyrosinase gene (Ruppert et al. 1988). The deleted sequence of the Tyrs-33 corresponds to the nucleotide residues $1021 / 1168$ of the $\mathrm{pHT} \gamma \mathrm{l}$ (Fig. 3, indicated by a dotted underline). It is therefore conceivable that mouse tyrosinase cDNA, Tyrs-33, is derived from an aberrant mRNA generated by alternative splicing of the primary transcripts as reported (Müller et al. 1988; Ruppert et al. 1988). The mouse tyrosinase deduced from Tyrs-33 (Yamamoto et al. 1987) thus lacks a putative $\mathrm{Cu}(\mathrm{B})$-binding region encoded by the exon 3 (Ruppert et al. 1988). We therefore assumed that the locations of introns in the human tyrosinase gene are 


\section{M1 A B M2}

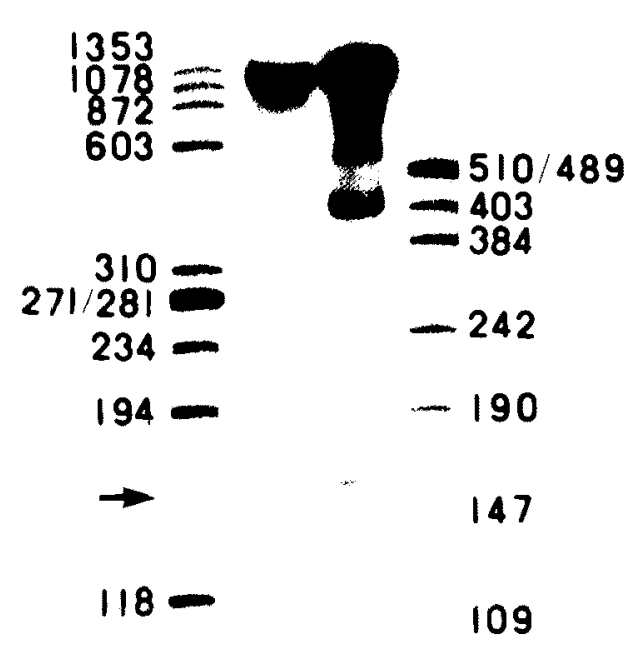

78

72

67

Fig. 5. Presence of aberrant species of human tyrosinase mRNA. The presence of aberrant $m R N A$ was analyzed by $S 1$ mapping. The $S 1$ probe is shown in Fig. 1. The size markers are end-labeled $\phi X 174$ DNA fragments (M1) and pUC8 DNA fragments (M2) (see Materials \& Methods) and given in base pairs. The arrow indicates the protected fragments. Lane A, control with HeLa RNA and lane $\mathrm{B}$, with MeWo RNA.

between the nucleotide residues 1020 and 1021 , and 1168 and 1169 of $\mathrm{pHT} \gamma 1$ (indicated by dotted vertical lines in Fig. 3) and analyzed RNA prepared from MeWo human melanoma cells in order to confirm the presence of such an aberrant tyrosinase mRNA. The $\mathrm{S} 1$ probe was the PstI/BglII fragment (vector/1314) shown in Fig. 1 and the BglII site is located about 150 nucleotides downstream from the putative intron/exon junction (Fig. 3). The results showed protected fragments of about 150 nucleotides (Fig. 5), indicating that the sequence of some tyrosinase mRNA is different around the nucleotide residue 1168 of the $\mathrm{pHT} \gamma 1$. Since we used total RNA, it is possible that our RNA preparation contains heterogenous nuclear RNA prior to splicing. The protected fragments therefore may represent such unspliced RNAs. Alternatively, the results may indicate the presence of aberrant RNAs like the one for mouse tyrosinase cDNA, Tyrs-33 (Yamamoto et al. 1987). Considering all these observations, we propose that there are at least two distinct species of human tyrosinase mRNAs, which are 
generated by alternative splicing. Since such aberrant tyrosinase encoded by Tyrs-33 lacks the $\mathrm{Cu}(\mathrm{B})$-binding site, it may not be functional. Further studies are required to identify the physiological role of such aberrant tyrosinase.

Recently, we have confirmed that the tyrosinase gene is present and its overall structural organization seems to be unchanged in a patient with oculocutaneous albinism (Tomita, Tagami and Shibahara, unpublished observations). We are currently attempting to isolate and characterize the tyrosinase gene of this patient. The sequence data presented in this paper will enable us to look for the mutations in the tyrosinase gene of albino patients.

\section{Acknowledgments}

We thank Prof. R. Lontie for communicating unpublished data. We also thank Drs. B. Hemmings and J.-P. Jost for helpful comments and critical reading of the mnuscript.

This work was supported in part by Grants-in-Aid for Scientific Research (Nos. 62570448 and 63570466) from the Ministry of Education, Science and Culture of Japan.

\section{References}

1) Aviv, H.T. \& Leder, P. (1972) Purification of biologicaliy active globin messenger RNA by chromatography on oligothymidylic acid-cellulose. Proc. nat. Acad. Sci. USA, 69, 1408-1412.

2) Bause, E. (1983) Structural requirements of N-glycosylation of proteins. Biochem. J., 209, 331-336.

3) Brüggen, J., Macher, E. \& Sorg, C. (1981) Expression of surface antigens and its relation to parameters of malignancy in human malignant melanoma. Cancer Immunol. Immunother, 10, 121-127.

4) Burnet, J.B., Seiler, H. \& Brown, I.V. (1967) Separation and characterization of multiple forms of tyrosinase from mouse melanoma. Cancer Res., 27, 880-889.

5) Feinberg, A.P. \& Vogelstein, B. (1983) A technique for radiolabeling DNA restriction endonuclease fragments to high specific activity. Anal. Biochem., 132, 6-13.

6) Hearing, V. J., Ekel, T.M. \& Montague, P.M. (1981) Mammalian tyrosinase: Isozymic forms of the enzyme. Int. J. Biochem., 13, 99-103.

7) Kwon, B.S., Haq, A.K., Pomerantz, S.H. \& Halaban, R. (1987) Isolation and sequence of a $c$ DNA clone for human tyrosinase that maps at the mouse c-albino locus. Proc. nat. Acad. Sci. USA, 84, 7473-7477.

8) Kwon, B.S., Wakulchik, M., Haq, A. K., Halaban, R. \& Kestler, D. (1988) Sequence analysis of mouse tyrosinase CDNA and the effect of melanotropin on its gene expression. Biochem. biophys. Res. Commun., 153, 1301-1309.

9) Lerch, K. (1988) Protein and active-site structure of tyrosinase. In: Advances in Pigment Cell Research, edited by J.T. Bagnara, Alan R. Liss, New York, pp. 85-98.

10) Lerner, A.B., Fitzpatrick, T.B., Calkins, E. \& Summerson, W.H. (1950) Mammalian tyrosinase: The relationship of copper to enzymic activity. J. biol. Chem., 187, 793802.

11) Marshall, R.D. (1974) The nature and metabolism of the carbohydrate-peptide linkages of glycoproteins. Biochem. Soc. Symp., 40, 17-26.

12) Maxam, A.M. \& Gilbert, W. (1980) Sequencing end-labeled DNA with base-specific chemical cleavages. Meth. Enzymol., 65, 499-560.

13) Müller, G., Ruppert, S., Schmid, E. \& Schutz, G. (1988) Functional analysis of alternatively spliced tyrosinase gene transcripts. EMBO J., 7, 2723-2730.

14) Müller, R. M., Taguchi, H. \& Shibahara, S. (1987) Nucleotide sequence and organiza- 
tion of the rat heme oxygenasegene. J. biol. Chem., 262, 6795-6802.

15) Nishioka, K. (1978) Particulate tyrosinase of human malignant melanoma. Europ. J. Biochem., 85, 137-146.

16) Ohkura, T., Yamashita, K., Mishima, Y. \& Kobata, A. (1984) Purification of hamster melanoma tyrosinase and structural studies of their asparagine-linked sugar chains. Arch. Biochem. byophys., 235, 63-77.

17) Okayama, H. \& Berg, P. (1982) High-efficiency cloning of full-length cDNA. Molec. cell. Biol., 2, 161-170.

18) Pomerantz, S.H. (1966) The tyrosine hydroxylase activity of mammalian tyrosinase. $J$. biol. Chem., 241, 161-168.

19) Pomerantz, S.H. \& Li, J. P-C. (1973) Purification and properties of tyrosinase isoenzymes from hamster melanoma. Yale J. biol. Med., 46, 541-552.

20) Ruppert, S., Müller, G., Kwon, B. \& Schutz, G. (1988) Multiple transcripts of the mouse ty rosinase gene are generated by alternative splicing. EMBO $J ., 7,2715-2722$.

21) Shibahara, S., Tomita, Y., Sakakura, T., Nager, C., Chaudhuri, B. \& Müller, R. (1986) Cloning and expression of cDNA encoding mouse tyrosinase. Nucleic Acids Res., 14, 2413-2427.

22) Shimao, K. (1962) Partial purification and kinetic studies of mammalian tyrosinase. Biochim. biophys. Acta (Amst.), 62, 205-215.

23) Yamamoto, H., Takeuchi, S., Kudo, T., Makino, K., Nakata, A., Shinoda, T. \& Takeuchi, T. (1987) Cloning and sequencing of mouse tyrosinase cDNA. Jap. J. Genet., 62, 271-274. 